\title{
Profesionalización de los gabinetes de prensa municipales
}

\author{
Dra. $\mathrm{M}^{\mathrm{a}}$ Luisa Cárdenas Rica \\ Profesora de Ciencias de la Comunicación en CEADE
}

La llegada de la democracia y el nuevo orden político obliga a los ayuntamientos a crear servicios comunicativos que revaloricen su imagen y su credibilidad frente a la opinión pública. La autora defiende la profesionalización de los gabinetes de prensa municipales, para evitar que la información institucional se convierta en fuentes informativas interesadas. Es necesario que los periodistas que trabajan en dichos gabinetes sean profesionales al servicio de los ciudadanos y no de los intereses políticos. Su gestión en el gobierno local ha de ser apolítica. Su misión es servir a la prensa no a un partido.

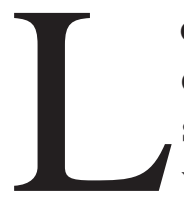

os Gabinetes de Prensa Municipales se han ido instalando en España con la llegada de la democracia. La Administración se hace más sensible a los juicios de la opinión pública, por lo que ha de revalorizar su imagen y su credibilidad. Tiene que someterse al control que ejercen las urnas, y sus representantes corren el riesgo de no salir reelegidos si la opinión general no les es favorable.

Las necesidades del nuevo orden político conducen a los municipios a crear servicios comunicativos que permitan la relación con sus convecinos, utilizando de intermediarios a los medios de comunicación.

El gran interés mostrado por los medios sobre los temas de ámbito local, alerta para que se construyan barreras que eviten que la información institucional se convierta en fuentes de primer orden con tintes propagandísticos. Por ello, se propone, entre otras medidas, que sus técnicos sean profesionales al servicio de los ciudadanos y no de los intereses políticos.

\section{Democracia y comunicación municipal}

Los Gabinetes de Prensa de los Ayuntamientos se han ido multiplicando en España a partir del segundo mandato municipal (1983-87) de la etapa 
democrática iniciada, a partir de 1976. Será con la llegada de ésta última cuando comiencen a asignárseles partidas presupuestarias, al incluir la Administración local en su gestión acciones comunicativas ${ }^{1}$. «Se pasa del secreto a la transparencia» ${ }^{2}$. Su principal objetivo es tener eco en los medios de comunicación, permitiéndoles, a su vez, mantener informados a los ciudadanos sobre la labor desarrollada por el ayuntamiento. Picos Freire ${ }^{3}$ expresará que las corporaciones locales, e incluso antes de ser dotadas con una ley que recogiera los aspectos de participación y comunicación, fueron las pioneras en lanzarse a desarrollar sistemas de información cercana.

El origen de los Gabinetes está relacionado con la democracia, porque este sistema exige unos comportamientos morales y éticos a todos los ciudadanos, no siendo posible un digno ejercicio profesional sin esa apelación superior a las conductas citadas ${ }^{4}$.

$\mathrm{Su}$ nacimiento viene amparado en el Reglamento de Organización, Funcionamiento y Régimen Jurídico de las Entidades Locales (ROF), en su artículo 230. En el que se expresa que existirá, en la organización administrativa de la Entidad, una Oficina de Información que canalizará toda la actividad relacionada con la publicidad, de este modo se recoge la existencia de los Gabinetes de Prensa Municipales. Añadiéndose que «la Oficina de Información podrá estructurarse de forma desconcentrada si así lo exige la eficacia de su función». Aclara que las peticiones de información deberán ser razonadas. También la Constitución Española contempla en el artículo 20 la libertad de expresión y derecho a la información y, además, en el artículo 105 establece el derecho de acceso a los archivos y registros públicos de todos los ciudadanos con excepción de los que queden protegidos por la ley de Secretos Oficiales y de aquellos otros datos que comprometan la intimidad de las personas. Y en la Ley de Base de Régimen Local, en el artículo 69, se recoge que las corporaciones locales «facilitarán la más amplia información sobre su actividad y la participación de todos los ciudadanos en la vida local».

\footnotetext{
PÉREZ GONZÁLEZ, R. A.: Un modelo estratégico de comunicación municipal, Tesis doctoral, Ed. Universidad Complutense, Madrid, 1988, págs. XX-XXI

2 PÉREZ VARELA, Jesús: «La comunicación política en el sistema democrático», en AA. VV.: La comunicación Política, Ed. Diputación de Pontevedra, Pontevedra, 1996, págs. 72-73.

3 PICOS FREIRE, José J.: «Estructura de la prensa local en España», en AA.VV.: Manual de periodismo, Ed. Prensa Ibérica, Universidad de Las Palmas de Gran Canaria, Barcelona, 1995, pág. 608.

4 GELONCH i VILADEGUT, A.: «Acción Política y RR.PP.», en BARQUERO CABRERO, José Daniel (director): Manual de relaciones públicas empresariales, Ed. Gestión 2000, Barcelona, 1994, pág. 213.
} 


\section{Objetivos de la Información Institucional}

Este nuevo sistema político va a cambiar también las relaciones entre Administración y administrados. Al convertirse, la primera, en agente de desarrollo económico y garantía del progreso social, interviene prácticamente en todos los sectores y su acción alcanza igualmente a todos los ciudadanos. Se vuelve «cada vez más sensible y vulnerable a los juicios de la opinión pública, por lo que busca revalorizar su imagen y ganar credibilidad» 5 . Porque la instauración de la Constitución provocará, además, en este país, el aumento de poder de la opinión pública y la liberalización de los medios de comunicación.

El objetivo de la información institucional será, como expresa Martínez Bargueño ${ }^{6}$, identificar y desarrollar al máximo las relaciones con los ciudadanos, con vista al reforzamiento del conocimiento que éstos poseen de la Administración, y procurar el consenso en torno a su gestión. Porque el ayuntamiento no puede actuar sin contar con la opinión pública, pues, «los representantes políticos correrían el riesgo de no salir reelegidos como consecuencia de la opinión crítica sobre la gestión de su mandato» 7 . Tienen el deber de someterse «al control democrático y de presentar, por lo menos, sus balances de gestión periódicamente.» ${ }^{8}$. Además, la creciente complejidad de las gestiones administrativas requiere ser explicada, porque sino obstaculizará la exigencia, por parte de las asociaciones de barrio y de vecinos, de una democracia local participativa ${ }^{9}$.

\section{La obligación de informar de las Administraciones Públicas}

Los ciudadanos tienen el derecho a saber quiénes son los responsables de las distintas áreas, qué actividades se desarrollan y cuáles son sus costes. Black dirá que el gobierno municipal es una responsabilidad compartida «el principal objetivo es desarrollar una mayor conciencia cívica y estimular a la gente para que se tome un interés activo por su gobierno local»10. Para

\footnotetext{
MARTÍNEZ BARGUEÑO, M.: «Información administrativa un derecho constitucional», en AA.VV.: Información Institucional. Primeros encuentros, Ed. Generalitat Valenciana, Valencia, 1985, págs. 17-18.

6 Ibídem, págs. 16-17

PÉREZ GONZÁLEZ, R. A.: Op. cit, pág. 179.

8 PÉREZ GONZÁLEZ, R. A. y MAZO DEL CASTILLO, J. M.: «Metodología de configuración de cultura e imagen institucional», en AA.VV.: Diseño e imagen corporativa en las instituciones públicas, Ed. Instituto de la Pequeña y Mediana Empresa Industrial (IMPI), Madrid, 1989, pág. 12.

9 MIÈGE, Bernard: La sociedad conquistada por la comunicación, PPU, Barcelona, 1992, págs. 103-104.

${ }^{10}$ BLACK, Sam: Las relaciones públicas. Un factor clave de gestión, Ed. Hispano Europea, Barcelona, 1991, pág. 191.
} 
ello, será imprescindible propiciar una mayor predisposición de colaboración por parte de los vecinos y que la Administración les rinda cuentas.

Como puede observarse, las necesidades generadas por el nuevo orden político conducen a los municipios a crear servicios comunicativos que permitan las relaciones con los ciudadanos, utilizando de intermediarios a los medios de comunicación privados y a los de propia creación y gestión. Esta asistencia la ofrecerán los Gabinetes de Comunicación locales, a los que son necesario observar como fuentes de información, generadores de la imagen municipal e influyentes en los medios. Determinados sectores los definen como simples aparatos propagandísticos, mientras que otros los estiman imprescindibles fuentes de información ${ }^{11}$.

Atendiendo a una definición más exacta, serán descritos como fuentes activas, organizadas y habitualmente estables de comunicación que cubren las necesidades informativas de distintas organizaciones que aspiran a tener resonancia en la opinión pública ${ }^{12}$.

El Gabinete de una corporación local sirve para sacar los asuntos públicos a la calle y acercar la Administración Pública a sus administrados, haciéndoles llegar los acontecimientos municipales y locales, en contacto directo con los medios de comunicación. Crean entre otras funciones los suyos propios: revistas municipales, emisoras locales, televisiones por cable, etc.

Los Gabinetes Municipales, según un estudio realizado en los Ayuntamientos de la provincia de Sevilla ${ }^{13}$, fundamentan su actuación en sus relaciones con los medios, por lo que reciben el nombre de Gabinete de Prensa ${ }^{14}$. Atender a las peticiones del gran número de medios existentes en la actualidad, no es tarea fácil. La cuestión se complica cuando, además, existe interés en mantener constantemente informada a la población ${ }^{15}$. En este aspecto radica la función del Gabinete, en satisfacer dichas necesidades comunicativas. Para lo que establecerán sistemas diseñados que proyecten la información necesaria. Con la ventaja que posee la Administración, al ocu-

\footnotetext{
11 RAMÍREZ, Txema: «La influencia de los gabinetes de prensa. Las rutinas periodísticas al servicio del poder», en TELOS, $\mathrm{N}^{\circ}$ 40, Madrid, diciembre-febrero, 1995, pág. 47.

12 Ibídem, pág. 47.

${ }^{13}$ CÁRDENAS RICA, Ma Luisa: Los Gabinetes de Prensa Municipales en la provincia de Sevilla, Tesis doctoral sin publicar, FCCI, Sevilla, 1998.

${ }^{14}$ CASTILlO, J. del, BAYÓN, M., y ARTETA, R.: La empresa ante los medios de comunicación, Deusto, Bilbao, 1992, pág. 189.

15 RAMÍREZ, Txema: Art. cit., pág. 50.
} 
par el centro de atención de los medios, gran parte de la gestión que desarrolla se transforma en noticia.

Para Weil, la comunicación institucional «apareció para subrayar una novedad: la de un discurso que no estaba directamente destinado a vender un producto»16. Añadirá que el objetivo que persigue es dar a conocer su voluntad y suscitar la adhesión a su proyecto.

\section{Interés por los temas locales}

El acceso de la corporación local a los medios vendrá dado gracias a la apertura informativa que experimenta esta primera, como se expresaba anteriormente; a lo que hay que unir el requerimiento de los segundos por introducir información cercana, entre la que se incluye la generada por el gobierno municipal ${ }^{17}$. La inclusión de los temas locales también está motivada por los deseos del lector afincado en este ámbito, ciudades y pueblos de la geografía española.

El interés manifestado va a propiciar el nacimiento de los medios locales, porque como expresa Maciá si es regional o nacional nunca satisface plenamente el derecho de saber del receptor, «en lo que se refiere a su contidianidad más inmediata, no llega a una profundización tan de cerca ni al detalle a un conocimiento tan próximo. Por razón del espacio disponible, así como la estructura redaccional, ninguna crónica de corresponsal puede competir con la prensa 'in situ'» 18 .

En la «Edimburg Review», en 1837, un autor anónimo escribía: «Por baratos que sean los libros y por muy popular que sea su lenguaje, es difícil que los lean ignorantes... Pero en cambio todos los hombres leerán las noticias; y tratándose del periódico que publica la crónica de lo sucedido en el mercado de la ciudad vecina, hasta los campesinos, los mozos de cuadra y los jornaleros, no sólo lo leerán, sino que lo devorarán» 19 .

\footnotetext{
16 WEIL, Pascale: La comunicación Global. Comunicación Institucional y de gestión, Paidós Comunicación, Barcelona, 1992, pág. 25.

17 Así el diario El Mundo sintetiza los tres planos primordiales de la información local en sus páginas: «El político (las actividades de los cargos públicos y de los candidatos en períodos electorales; los plenos municipales). El económico-presupuestario (gasto, inversiones y tasas municipales). El urbanístico (planificación, cambios de uso, obras públicas). Y aunque se expresa que las ciudades «no son sólo su Casa Consistorial», se observa en los tres planos citados la figura del ayuntamiento. AA.VV.: Libro de Estilo de El Mundo, Ed. Temas de Hoy, Madrid, 1996, pág. 38.

18 MACIÁ MERCADÉ, Juan: La comunicación regional y local: dinámica de la estructura de la información en la España de las Autonomías, Ed. Ciencia 3, Madrid, 1993, págs. 181-182.

${ }_{19}$ Citado por MACIÁ MERCADÉ, J.: Op. cit., pág. 183.
} 
De ahí que proliferen los medios comarcales o locales que, como continúa indicando Maciá20, se aproximan mucho más al lector y le informan de lo cotidiano e inmediato.

\subsection{Medios impresos}

Los precedentes de los medios actuales de información próxima se encuentran en la prensa regional del siglo XIX, periódicos que van a sobrevivir al régimen franquista, entre ellos $A B C$ (en sus ediciones de Sevilla y Madrid), Pueblo (con varias ediciones desde 1960 en Sevilla, Bilbao, Valladolid, Zaragoza y un proyecto en Valencia), El Correo Español, La Gaceta del Norte (desaparecida), La Voz de Galicia, La Verdad y El Norte de Castilla ${ }^{21}$.

$\mathrm{Su}$ potenciación actual se produce con la liberalización del sistema político y la llegada de la democracia, especialmente a partir de 1976. Su auge, en medio de la crisis de los diarios nacionales, cobra pleno sentido en el marco de las autonomías. Dado el control de los medios audiovisuales, la importancia de la prensa escrita en el proceso autonómico es decisiva ${ }^{22}$.

Junto a la facilidad de emitir mensajes a través de la creación de nuevos medios, también se produce la permeabilidad de éstos, gracias a la creación de la sección Local y en ella la subsección de Provincia, abordando la actualidad de los municipios. Así, por ejemplo, los diarios hispalense han sido partícipes de la localización informativa: ABC en su edición de Sevilla, Diario 16-Andalucía y El Correo de Andalucía 23.

Esta atención por lo local será aprovechada por los Gabinetes de Prensa Municipales que han adquirido habilidad para romper la censura de los grandes medios contra su expresión cotidiana, terminan «con la impermeabilidad de los masivos instrumentos de comunicación» 24 . Estos datos también quedan reflejados en el estudio realizado de estos Gabinetes en la Provincia de Sevilla ${ }^{25}$ y su repercusión en los contenidos de la prensa, gracias a una relación directa y permanente.

\footnotetext{
${ }^{20}$ Ibídem, pág. 152.

${ }^{21}$ PICOS FREIRE, J. J.: Op. cit., pág. 607.

22 PÉREZ VILARIÑO, José: Los periódicos ante las autonomías, Akal Ed., Madrid, 1984, págs. 8-9.

${ }^{23}$ CÁRDENAS, M. L., y GONZÁLEZ, A.: «Información local: democratización e interacción comunicacional», en AA.VV.: Comunicar: aprender a vivir. Congreso Universitario Internacional, Ed. Kronos, Sevilla, 1996, pág. 76.

${ }^{24}$ RUIZ DEL ÁRBOL, Antonio: 1970-1980. Diez años de prensa local madrileña, Ed. Comunidad de Madrid, Consejería de Gobernación y Consejería de Cultura y Deportes, Madrid, 1987, pág. 18.

${ }^{25}$ CÁRDENAS, M ${ }^{\mathrm{a}}$ L.: Los Gabinetes de Prensa Municipales ... Op. cit.
} 
En resumen, se observa cómo la información local se ve favorecida, por un lado, por la proliferación de los medios locales que van a imitar a los grandes diarios; mientras que estos últimos van a crear secciones referidas a este ámbito o van a edicionalizar sus contenidos para acercarse lo más posible a la comarca y a la localidad, esto se consigue cambiando una parte de su paginación, para lograr un nuevo producto para una distinta zona.

\subsection{Cambios en los medios audiovisuales}

Los medios audiovisuales se suman a las modificaciones, como expresa Cal Martínez, la TV estatal comenzó a descentralizarse con la concesión de los canales autonómicos y la de carácter local también hace su aparición, «fruto de las corporaciones locales en un alto porcentaje, conjuntamente con agrupaciones ciudadanas» 26 .

En 1983 se aprobó la Ley Orgánica que regirá la radiodifusión en las autonomías. La transición política propició el gran auge de las emisoras de radio entre ellas las municipales, entes de titularidad pública que pertenecen a la Administración local. Se llegan a crear distintas asociaciones que las agrupan, en Andalucía se constituye las Emisoras Municipales de Andalucía (EMA), en Cataluña Emisoras Municipales de Cataluña (EMUC), entre otras. Los principios que van a seguir son especialmente: la participación democrática, descentralización y servir a la autonomía municipal ${ }^{27}$.

Las relaciones del gobierno local tanto con la radio y la televisión no son tan continuas como con la prensa, pero habitualmente su impacto es más poderoso. Y también sus productores están interesados en recibir información sobre cualquier actividad característica o inusual generada en este ámbito, que pueda constituir la base de un programa o de un reportaje.

Todo lo expresado conduce a que la Administración aproveche tanto el crecimiento de los medios cercanos como el interés que los ciudadanos manifiestan por ellos. Porque estos medios son una de las vías más efectivas para la comunicación entre el ayuntamiento y sus públicos. Por lo tanto, «es conveniente no regatear esfuerzos para establecer y mantener buenas relaciones, para que los asuntos locales reciban un tratamiento informativo tan completo y objetivo como sea posible» 28 .

\footnotetext{
${ }^{26}$ CAL MARTÍNEZ, Ma Rosa: «Fórmulas nuevas de información local», en AA.VV.: Historia de los medios de comunicación en España. Periodismo, imagen y publicidad (1900-1990), Ariel Comunicación, Barcelona, 1989, págs. $489-490$.

${ }^{27}$ Ibídem, págs. 490-491.

${ }^{28}$ BLACK, Sam: Op. cit., pág. 194.
} 


\section{Profesionalización ante la politización de la información municipal}

Conseguir un modelo para la comunicación municipal precisa el análisis de numerosos condicionamientos generales, requiere un examen crítico sobre la gestión que desarrolla la institución, en este campo, y el servicio que presta a los ciudadanos. Controlar la forma en que se divulga la actuación municipal y prever el impacto que tendrá en la opinión pública, constituye «una apuesta por la eficacia»29. Por ello, hay que prestar atención a lo expresado por Fernández Areal, quien argumenta que es racional que el Estado opine, aunque no lo es, y constituye un abuso de poder, que trate de orientar la información, «coloreándola, desvirtuándola, haciendo de ella desinformación» 30 . Sobre todo, cuando además se detecta que todos los Gabinetes no reciben el mismo trato por parte de los medios, en relación a su presencia. Los institucionales, en los que se incluyen los municipales, van a aparecer frecuentemente, llegando a crear «conflictos de dependencia» 31 .

Una vez que la Administración descubre que «el silencio no es renta$b l e »^{32}$, se convierten en fuente informativa de primer orden dentro del proceso comunicativo, natural e imprescindible ${ }^{33}$. Este aspecto preocupa a los teóricos, reclaman una mayor participación de los ciudadanos en el sistema comunicativo y que los medios recuperen su sentido crítico. Y también exigen que se haga distinción entre propaganda ${ }^{34}$ y la función real de los Gabinetes. Black ${ }^{35}$ resume principalmente en dos los objetivos: dar habitualmente información sobre los planes y los logros de la institución, e informar y educar a los públicos sobre legislación, disposiciones y todos los asuntos que afectan a la vida diaria de los ciudadanos.

Se le reclama que no se convierta en un organismo para hacer política, existe «para servir a la prensa» ${ }^{36}$, y consecuentemente a los ciudadanos.

\footnotetext{
${ }^{29}$ CASTILlo, J. del, BAYÓN, M., y ARTETA, R.: Op. cit., págs. 122-123.

${ }^{30}$ FERNÁNDEZ AREAL, M: «El informador frente al Estado», en AA. VV.: La Comunicación Política.. Op. cit., págs. 43-44. «Tiene el Estado derecho y obligación de actuar como fuente informativa, tiene derecho igualmente a opinar; a lo que no tiene derecho es a modelar la información imponiendo su opinión o su versión».

31 MACIÁ MERCADÉ, J.: Op. cit., pág. 154.

32 SCHMERTZ, H., y NOVACK, W.: El silencio no es rentable, Planeta, Barcelona, 1986.

33 CASTILlO, J. del, BAYÓN, M., y ARTETA, R.: Op. cit., pág. 144.

34 «Entendemos por propaganda política aquella comunicación persuasiva, fundamentalmente de masas, de carácter ideológico, realizada y/o impulsada directamente por los gobernantes, o gobernados relativamente influyentes de una sociedad, con el fin real o aparente de difundir tal ideología y obtener poder para realizar el bien común». ARCEO VACAS, J. L.: «Campañas», en BENITO, A. (director): Diccionario de ciencias técnicas y de la comunicación, Eds. Paulinas, Madrid, 1991, pág. 150.

35 BLACK, Sam: Op. cit., pág. 185.

36 Ibídem, pág. 69.
} 
Porque su gestión en el gobierno local ha de ser apolítica. Su misión, como se expresaba anteriormente, «es promover la democracia e informar a los ciudadanos por medio de una información completa» 37 y no en hacer progresar a un partido.

Por ello, como sigue argumentando Black ${ }^{38}$, será un error que el gobierno no cuente en la plantilla de funcionarios con expertos en estos temas, pues, si realizan bien su trabajo redundará en el crédito de un determinado concejal de un partido concreto; pero esto también ocurre con cualquier funcionario de otro departamento. Los años de experiencia deben servir para trazar una línea definida entre la información oficial y la propaganda de partido, entre la coyuntura del departamento y la plataforma política; los cargos públicos lo saben y también sus funcionarios.

Como bien se expresó en el II Congreso de la Comunicación Corporativa ${ }^{39}$, el hecho de que los periodistas del Servicio de Comunicación sean funcionarios de oposición garantiza una estancia en el servicio mucho más largo, lo que redunda en un mejor conocimiento de las estructuras administrativas que atienden. La estabilidad del citado Servicio y el mantenimiento de sus normas de funcionamiento y contenidos generan confianza en los medios de comunicación. Hace disminuir los recelos habituales ante una información procedente de un Gabinete de Prensa. Ello produce una visión más coherente y global de lo que es la institución pública y evita el distanciamiento de la actualidad puramente política respecto del conjunto de la entidad institucional.

Como ya se argumentaba, para el gobierno, en principio, toda información ha de estar subordinada al bien público, busca la utilidad general, atendiendo al terreno de los grandes principios. Es decir, al Estado le interesa que la información sea siempre beneficiosa para el Estado, lo que él representa y a los ciudadanos a los que sirve. Porque en cuanto se introduzca

\footnotetext{
37 Id., pág. 186.

${ }^{38}$ Id., pág. 190. Información que justifica lo expresado en la Administración andaluza, en una carta remitida por los profesionales de la información de la Junta de Andalucía. El 23 de noviembre de 1995 el colectivo de periodistas y gráficos que trabajan en las distintas Consejerías informan a la Mesa de Convenio Colectivo sobre su situación laboral: «Todo el personal ha accedido como personal eventual de la Consejería de Presidencia. (...) Nuestra forma de contratación no ha variado y, legislatura tras legislatura, tenemos que ser cesados y nombrados de nuevo, como si nuestra preparación académica y experiencia profesional no fuese suficiente aval para garantizar nuestra estabilidad laboral».

39 Vid. CARMONA SALINAS, J. F.: «El servicio de comunicación profesionalizado en una institución pública. El caso del Gobierno de Navarra», en II Congreso de la Comunicación Corporativa. La comunicación en las economías inteligentes, ACEI, Madrid, octubre, 1996.
} 
la finalidad en el proceso informativo, se pasa al campo de la propaganda o, al menos, al campo de la opinión ${ }^{40}$.

Por ello, los Gabinetes, en cuanto son requeridos por la comunidad ciudadana, deben mantener la suficiente independencia profesional para que jamás se conviertan en instrumentos de manipulación social, ni por tanto en meras herramientas publicitarias o propagandísticas de la institución públi$\mathrm{ca}^{41}$. Siendo preciso reclamar para sus profesionales, al igual que se le reconoce al periodista de los medios, la cláusula por la que pueden rechazar la intervención en un asunto que fuese contra sus convicciones justificadas, del mismo modo el periodista de los Gabinetes de Prensa deberá tener «reconocida la facultad de no cooperar en informes que careciesen de veracidad o ética» 42 .

El sistema eficaz consistiría en proporcionar a sus especialistas los recursos adecuados para hacer frente a las exigencias de la zona en la que trabajan. Aunque también todos los miembros de un ayuntamiento y su administración deben ser conscientes de la necesidad de seguir los principios que mueven la comunicación institucional, por lo que deberán fomentar la confianza mutua. La confidencialidad es imprescindible en este terreno y los profesionales han de respetar los códigos de conducta aplicables al respecto. Ésta es «particularmente importante cuando se trabaja en el gobierno central o local» 43 .

Lo que resulta evidente es que si no se ponen los controles necesarios, como expresa Ángel Benito, a la denominada Información Institucional y, sobre todo, si los medios de comunicación no establecen los exámenes oportunos para asegurar la autenticidad de las fuentes, la comunicación difundida por la Administración «llegará a ser un instrumento de dominación»44.

En España la comunicación política y la difundida por el gobierno municipal están muy próximas, y pese a la transformación que han experimentado los ayuntamientos con la democracia, aún es largo el camino; la comunicación municipal busca todavía su identidad. Su propia función es poco

\footnotetext{
${ }^{40}$ FERNÁNDEZ AREAL, Manuel: Op. cit., pág. 35.

${ }^{41}$ ENEBRAL, F.: Función social de los Gabinetes de Prensa, Tesina de convalidación, sin publicar, FCCI, dirigida por Javier Fernández del Moral, Madrid, 1989, pág. 73.

42 Ibídem, pág. 73.

43 BLACK, S.: Op. cit., págs. 196-197.

${ }^{44}$ BENITO, A.: «Información intencional y tecnología», en Curso de Verano de El Escorial: Información, Política y Cultura, Universidad Complutense, Madrid, 1988, pág. 31.
} 
reconocida y a menudo justamente identificada con la comunicación política; «los miembros de su personal tiene un estatuto tan particular que no saben si deben presentarse como periodistas o como asistentes políticos» ${ }^{45}$.

${ }^{45}$ MIÈGE, B.: Op. cit., pág. 108. 